\title{
A concepção de educação ambiental dos professores do Ensino Fundamental II: apontando elementos para uma reflexão crítica
}

\author{
The conception of environmental Education Elementary school teachers II: pointing elements to \\ critical reflection \\ La concepción de la educación ambiental maestros de Escuela Primaria II: apuntar elementos a la \\ reflexión crítica
}

Recebido: 12/08/2021 | Revisado: 18/08/2021 | Aceito: 23/08/2021 | Publicado: 25/08/2021

\author{
Adalberto Freire da Silva \\ ORCID: https://orcid.org/0000-0001-5300-2729 \\ Escola Estadual de Ensino Fundamental Osvaldo Aranha, Brasil \\ E-mail: adal.freire@ terra.com.br \\ Vidica Bianchi \\ ORCID: https://orcid.org/0000-0003-0277-0191 \\ Universidade Regional do Noroeste do Estado do Rio Grande do Sul, Brasil \\ E-mail: vidica.bianchi@unijui.edu.br \\ Maria Cristiana Pansera de Araújo \\ ORCID: https://orcid.org/0000-0002-2380-6934 \\ Universidade Regional do Noroeste do Estado do Rio Grande do Sul, Brasil \\ E-mail: pansera@unijui.edu.br
}

\begin{abstract}
Resumo
Numa perspectiva de refletir sobre a concepção ambiental dos professores do Ensino Fundamental II que atuam em várias áreas do conhecimento, apresentamos para o debate as concepções de Educação Ambiental Crítica e da Educação Ambiental Conservadora, tendo como foco as respostas dos professores a seguinte questão: "Como você define Educação Ambiental?" O objetivo foi analisar a partir das respostas dos professores as concepções no que se refere a Educação Ambiental para uma tomada de consciência quanto às questões socioambientais e como estas interferem na sua prática pedagógica. Realizou-se uma pesquisa qualitativa, em que o material empírico foi produzido a partir das respostas a um questionário submetido a professores de diversas níveis e áreas do conhecimento. Os resultados apontam que muitos dos entrevistados enfatizam o meio ambiente como sendo a natureza, o local onde se vive e de onde se extraem recursos. Uma outra parcela dos entrevistados pensa a Educação Ambiental de maneira crítica, pois percebemna fundamental, na busca do diálogo entre ação-reflexão-ação em torno das vivências cotidianas. Já uma parcela menor dos professores não conseguiu definir Educação Ambiental, demostrando que não há um conhecimento real sobre ela, que pode ser consequência de uma deficiência na formação inicial e continuada. Este resultado aponta para a necessidade de uma mudança na forma como é tratada a Educação Ambiental na formação dos professores.
\end{abstract}

Palavras-chave: Educação ambiental; Cidadania; Meio ambiente.

\begin{abstract}
From the perspective of reflecting on the environmental conception of elementary school teachers II who work in various areas of knowledge, we present for the debate the conceptions of Critical Environmental Education and Conservative Environmental Education, focusing on the answers of teachers to the following question: "How do you define Environmental Education?" The objective was to analyze from the teachers' answers the conceptions regarding Environmental Education for an awareness of social and environmental issues and how they interfere in their pedagogical practice. A qualitative research was carried out, in which the empirical material was produced from the answers to a questionnaire submitted to teachers of various levels and areas of knowledge. The results indicate that many of the interviewees emphasize the environment as nature, the place where one lives and where resources are extracted. Another portion of the interviewees thinks about Environmental Education in a critical way, because they perceive it as fundamental, in the search for dialogue between action-reflection-action around daily experiences. On the other hand, a smaller portion of teachers could not define Environmental Education, showing that there is no real knowledge about it, which may be a consequence of a deficiency in initial and continuing education. This result points to the need for a change in the way environmental education is treated in teacher education.
\end{abstract}

Keywords: Environmental education; Citizenship; Environment.

\section{Resumen}

Desde la perspectiva de reflexionar sobre la concepción ambiental de los maestros de primaria II que trabajan en diversas áreas del conocimiento, presentamos para el debate las concepciones de Educación Ambiental Crítica y Educación 
Ambiental Conservadora, enfocándonos en las respuestas de los docentes a la siguiente pregunta: "¿Cómo se define la Educación Ambiental?" El objetivo fue analizar a partir de las respuestas de los docentes las concepciones sobre la Educación Ambiental para una conciencia de los problemas sociales y ambientales y cómo interfieren en su práctica pedagógica. Se realizó una investigación cualitativa, en la que el material empírico se produjo a partir de las respuestas a un cuestionario enviado a profesores de diversos niveles y áreas de conocimiento. Los resultados indican que muchos de los entrevistados enfatizan el ambiente como naturaleza, el lugar donde se vive y donde se extraen los recursos. Otra parte de los entrevistados piensa en la Educación Ambiental de manera crítica, porque la perciben como fundamental, en la búsqueda del diálogo entre acción-reflexión-acción en torno a las experiencias cotidianas. Por otro lado, una porción menor de los docentes no pudo definir la Educación Ambiental, mostrando que no existe un conocimiento real sobre ella, lo que puede ser consecuencia de una deficiencia en la educación inicial y continua. Este resultado apunta a la necesidad de un cambio en la forma en que se trata la educación ambiental en la formación del profesorado.

Palabras clave: Educación ambiental; Ciudadanía; Medio ambiente.

\section{Introdução}

A Educação Ambiental (EA) é uma ferramenta que pode contribuir para a formação de cidadãos mais conscientes e engajados em ações que possibilitem a resolução dos problemas ambientais enfrentados pela sociedade moderna. Problemas estes, causados principalmente pelo consumismo desenfreado, que aumenta a demanda da produção e consequentemente a retirada de matérias primas da natureza, pois utiliza muita energia elétrica e água, entre outros. Tudo isso, gera emissão de gases poluentes, degradação e devastação ambiental, poluição geral e, portanto, a destruição de ecossistemas. Entendemos que a EA pode motivar a reflexão sobre estes problemas e também propor estratégias e novas formas de agir na busca de solução dos mesmos.

No Brasil, a Lei nº. 6.938, de 31 de agosto de 1981, que dispõe sobre a Política Nacional de Meio Ambiente (PNMA), foi responsável pela inclusão do componente ambiental na gestão das políticas públicas e decisiva inspiradora do Capítulo do Meio Ambiente na Constituição Federal do Brasil, de 1988. No âmbito da educação, a lei 9.795, de 27 de abril de 1999 , instituiu a Política Nacional de EA, e, através do art. $2^{\circ}$, estabelece que "a EA é um componente essencial e permanente da educação nacional, devendo estar presente, de forma articulada, em todos os níveis e modalidades do processo educativo, em caráter formal e não formal" (Brasil, 1999).

Segundo a Política Nacional de entende-se por EA “os processos por meio dos quais o indivíduo e a coletividade constroem valores sociais, conhecimentos, habilidades, atitudes e competências voltadas para a conservação do meio ambiente, bem de uso comum do povo, essencial à sadia qualidade de vida e sua sustentabilidade" (Art. $1^{\circ}$ ) (Brasil, 1999). Tristão (2008, p. 20) compartilha dessa ideia afirmando que "a relação entre meio ambiente e educação para a cidadania assume um papel cada vez mais desafiador demandando a emergência de novos saberes para apreender processos sociais que se complexificam em riscos ambientais que se intensificam".

A EA, neste contexto é tida como elemento de uma cidadania compreensiva, que está intrinsecamente relacionada com uma nova configuração de afinidade com o ser humano/natureza e a sua grandeza cotidiana, isto induz a pensá-la como totalização de aprendizados e, logo, entendê-la na grandeza de suas potencialidades de generalizações para a sociedade em si (Tristão, 2008). Deste modo, percebe-se uma forte relação do meio ambiente e a educação, que desempenha uma ação mútua o que exige novos conhecimentos e práticas de relações sociais que perpassem o poder técnico e político dos gestores públicos com relação as questões ambientais.

A EA, portanto, está intrinsecamente relacionada às questões afetivas e à capacidade cognitiva para o entendimento do mundo através do olhar ambiental, promovendo assim mediações para os diversos entendimentos das experiências e relações sociais com o meio ambiente. Para Loureiro et al. (2009, p 85), “a EA no Brasil caracteriza-se pela explicitação das convergências e divergências, um momento de amadurecimento teórico e metodológico". Também salienta que os referenciais teóricos que dizem respeito à EA como prática social e ação política exigem um posicionamento claro. 
Neste sentido, o entendimento de ser humano e de educação em Freire (1996) compreende a educação como processo de conscientização, o que possibilita as pessoas tornarem-se sujeitos de sua própria história.

O que se coloca à educadora ou ao educador democrático, consciente da impossibilidade da neutralidade da educação, é forjar em si um saber especial, que jamais deve abandonar, saber que motiva e sustenta sua luta: se a educação não pode tudo, alguma coisa fundamental a educação pode. Se a educação não é a chave das transformações sociais, não é também simplesmente reprodutora da ideologia dominante. (p.126)

Portanto entendemos que a educação pode contribuir na construção de estratégias na busca de soluções aos problemas sociais e ambientais. Então podemos afirmar que EA, não significa somente enfatizar o conhecimento científico e tecnológico. Precisa também formar cidadãos que sejam capazes de buscar soluções para os problemas sociais, presentes no seu cotidiano, sem a necessidade de memorizar conceitos científicos prontos e acabados. Faz-se necessário um ensino que desafie os alunos desenvolverem a capacidade de enxergar os fenômenos científicos que acontecem nas mais variadas situações reais, que se apresentam em constante transformação.

Neste contexto, o objetivo desta pesquisa é discutir as concepções acerca da EA, dos professores do Ensino Fundamental II, que atuam em várias áreas do conhecimento. Com isto trazer para o debate as concepções de EA Crítica e da EA Conservadora, tendo como foco as respostas dos professores da seguinte questão: "Como você define Educação Ambiental?"

\section{Aspectos Teóricos}

A Educação Ambiental (EA) necessita reforçar o conhecimento cientifico através das representações sociais. No entanto, à qualidade de vida do ser humano perpassa diretamente pela preservação do meio ambiente, esta exige a busca de novas formas de pensar e agir para garantir a sustentabilidade ambiental. Sato (2001 a), reforça a importância da representação social da EA:

[...] cada pessoa ou grupo social pode ter a sua representação, ou a sua própria trajetória. O que é inadmissível é que as pessoas livrem-se do poder da criticidade e reproduzam discursos e práticas orientadas para desmobilização da EA, ora como gestão ambiental, ora como uma prática educativa qualquer. (p.8)

Ao refletirmos sobre uma definição para meio ambiente, deparamo-nos com inúmeras possibilidades, e que pode gerar muita polêmica. Muitos professores e pesquisadores buscam uma definição pronta e preestabelecida de meio ambiente, contrapondo-se ao nosso entendimento de que meio ambiente não é apenas a natureza, mas sim o lugar em que vivemos, nossa casa, nossa escola, as cidades, o planeta. Brandão (1985), reforça esta ideia:

[...] temas concretos da vida que espontaneamente aparecem quando se fala sobre ela, sobre seus caminhos, remetem a questões que sempre são as das relações do homem: com o seu meio ambiente, a natureza, através do trabalho; com a ordem social da produção de bens sobre a natureza; com as pessoas e grupos de pessoas dentro e fora dos limites das comunidades, da vizinhança, do município, da região; com os valores, símbolos, ideias. (p. 37-38)

Embora vários pesquisadores tentem estabelecer um consenso na definição de meio ambiente as especificidades do termo "meio ambiente" leva a várias concepções, na maioria das vezes dicotômicas, o que interfere diretamente na compreensão do verdadeiro sentido da EA. Muitos educadores pensam o meio ambiente em sua prática pedagógica somente como preservação da natureza, deixando de lado as questões culturais, sociais, econômicas, políticas e históricas.

Com relação a definição de EA, também não é diferente, existem muitas definições, umas ressaltam aspectos ecológicos da conservação, em que defendem a manutenção do ecossistema e outras com visões menos antropocêntricas e caráter 
conservacionista, deixando de lado a ideia de preservação somente da fauna e flora, assim o ser humano é visto como parte integrante da natureza.

Sauvé (2011) aborda as várias correntes da EA, as tradicionais que emergiram nas décadas de 70 e 80, quando se iniciou os debates em torno da EA, e as mais atuais. De acordo com esta pesquisadora, a EA possui diferentes discursos e propõem diversas maneiras de conceber e praticar a educação. Nessa perspectiva, analisou as várias propostas de EA e identificou quinze correntes. Este trabalho traz uma importante contribuição didática, pois possibilita estudantes e pesquisadores, acesso a uma verdadeira cartografia das propostas que existem na área. Dessa forma, fica o questionamento sobre as concepções que as pessoas têm a respeito da EA. Qual a concepção de EA dos professores? Esses professores têm acesso a esse mapeamento realizado por Sauvé? Compreender e apreender as correntes de EA é fundamental para os educadores desenvolverem uma consciência socioambiental e consequentemente qualificar sua prática pedagógica. Esta mudança na postura dos professores passa por processos formativos individuais e coletivos, assim, teremos mais possibilidades para que a EA se concretize no espaço escolar.

As correntes mais tradicionais fazem um confrontamento com as vertentes mais recentes, por exemplo no caso da conservacionista e a crítica, estas muito destacadas na análise das pesquisas em EA e que reforçam os compromissos sociopolíticos da mesma. Embora existam inúmeras correntes e classificações de EA, entendemos que para o objetivo desta pesquisa, é suficiente trabalhar com dois conceitos, buscando tornar este trabalho mais sintético e de fácil compreensão, já que o mapeamento das várias concepções de EA não é um consenso entre os pesquisadores, como reforça CARVALHO (2004) não é tarefa fácil localizar-se neste universo. Então optamos em traçar nosso debate entre a EA conservadora e a EA crítica.

\subsection{Educação ambiental conservadora}

Entendemos que a Educação Ambiental (EA) focada no comportamento do indivíduo e na produção de valores que influenciam no modo de agir, desvinculado da compreensão da divisão da sociedade em classes, é a principal particularidade da EA que se convencionou a se chamar de conservadora. Nesta perspectiva, a EA conservadora está centrada em práticas que se preocupam quase que exclusivamente com a preservação do meio ambiente, focado na ideia de que é dele que o ser humano obtém recursos. Para Guimarães (2007) essa concepção de EA simplifica ou reduz fenômenos complexos.

Esse caráter conservador prioriza ações pontuais, muitas vezes desconectadas da realidade, fragilizando ainda mais os processos educativos, principalmente a EA. Layrargues e Lima (2014) reforçam esta ideia:

(...) o predomínio de práticas educativas que investiam em crianças nas escolas, em ações individuais e comportamentais no âmbito doméstico e privado, de forma a-histórica, apolítica, conteudística e normativa não superariam o paradigma hegemônico que tende a tratar o ser humano como um ente genérico e abstrato, reduzindo-os à condição de causadores da crise ambiental, desconsiderando qualquer recorte social. (p. 29)

Nesta concepção de EA está fortemente enraizada a ideia de que a conscientização ecológica pode resolver a maior parte dos problemas ambientais. Conforme Guimarães (2007):

Essa educação não pode e/ou não quer perceber as redes de poder que estruturam as relações de dominação presentes na sociedade atual, tanto entre pessoas (relações de gênero, de minorias étnicas e culturais), entre classes sociais, quanto na relação "norte-sul" entre as nações, assim como também entre as relações de dominação que se construíram historicamente entre sociedade e natureza. São nessas relações de poder e dominação que podemos encontrar um dos pilares da crise ambiental dos dias de hoje (p.35).

Esta visão conservadora da EA reforça a metodologia informativa, enfatizando os fatores biológicos e ecológicos nas discussões ambientais, desconsiderando as disputas políticas e econômicas. Ou seja, essa concepção está centrada na ideia de que ações e mudanças individuais, podem resolver os problemas ambientais do Planeta. Essa perspectiva se mostra incapaz de 
entender complexidade e interagir de forma propositiva sobre a crise ambiental atual, visto que existem interesses de grupos mais fortes social e economicamente que prevalecem sobre a exploração descontrolada dos recursos naturais.

\subsection{Educação ambiental crítica}

Educação Ambiental (EA) crítica, trata as relações sociedade-natureza como uma questão sócio-política. Nesta visão Freire (2004) afirma que questões do mundo e suas mudanças estão presentes especialmente sob o foco da dimensão social dos ambientes de vida, em conexão com a responsabilidade ética das ações humanas: "[...] o mundo não é, o mundo está sendo [...]" (p. 79). Esta afirmação, implica diretamente nas ações socioambientais, que reforçam os valores e atitudes sustentáveis de vida. Podemos afirmar que EA Crítica contesta a concepção Conservadora, pois entendemos que essa questiona o sistema capitalista e se contrapõe a práticas predatórias motivadas pelo consumismo. Ou seja, a EA crítica busca construir, com diversos atores a cidadania socioambiental, pois traz para o centro do debate o cotidiano dos sujeitos tendo como meta a cidadania planetária.

Uma das características mais fortes da EA Crítica é questionar os sistemas econômicos e políticos que distorcem as reais causas da destruição do meio ambiente. Então, por se tratar de uma prática social, a EA precisa estar vinculada ao ecossistema e a sociedade, como forma de intervenção na realidade e de existência da natureza (LOUREIRO, 2007).

A EA Crítica aponta para uma conscientização ampla dos problemas ambientais, não responsabilizando a todos da mesma forma, considerando padrões de consumo. A EA Crítica destaca as questões sociais e questiona estas desigualdades. Como afirma Sato e Carvalho (2005, p.12) "a EA pode ser uma preciosa oportunidade na construção de novas formas de ser, pensar e conhecer, pois constitui um vasto campo de possibilidades de saberes. Enfim, a EA Crítica questiona a origem das ações que levam a destruição da natureza, não os métodos utilizados para atenuar as causas e os efeitos desta degradação, não comportando separações entre cultura/natureza, fazendo a Crítica ao modelo de sociedade vigente, sendo efetivamente autocrítica. Investigar e buscar entender as causas da poluição, do consumismo desenfreado, das desigualdades sociais, sempre com o objetivo de trazer à tona o papel da educação nesse contexto, com o intuito entender que é possível transformar a sociedade atual, são princípios básicos da EA. Como já dizia Freire (2000) "se a educação sozinha não transforma a sociedade, sem ela tampouco a sociedade muda" (p. 67).

Uma EA crítica, tem como foco, o ambiente e as relações sociais na mediação dos processos educativos. Portanto, os problemas acima focados são temas emergentes, que estão diretamente relacionados com o cotidiano dos sujeitos da educação. Ou seja, é a partir do contexto de vida dos educandos e dos entornos escolares que se pode refletir sobre essas questões, assim como a abordagem da sustentabilidade, numa leitura crítica da realidade, possibilitará a formação emancipatória dos sujeitosalunos, na construção da sua cidadania. Vasques e Messeder (2020, p.13) reforçam a ideia da educação como processo de formação humana e social, no qual se conecta também a educação ambiental.

A EA que acreditamos ser emancipatória, enxerga o meio ambiente, em toda a sua complexidade e suas inter-relações, que considera aspectos políticos, econômicos, culturais, ecológicos, históricos, entre outros. Assim, ao trazer para debate o conceito de meio ambiente, entende-se necessário aprofundar a compreensão de que não se trata apenas do meio natural, principalmente quando se refere a processos educativos, também é preciso considerar as relações sociais e de classe, onde o ser humano está inserido, pois o que buscamos é criar condições para uma sociedade mais justa e solidária.

\section{Metodologia}

Esta pesquisa é qualitativa, em que o material empírico foi produzido a partir das respostas a um questionário submetido a 80 professores de diversas níveis e áreas do conhecimento e a dois profissionais liberais. A pesquisa foi conduzida pelos professores e estudantes da turma do primeiro semestre de 2021 da Disciplina de Educação Ambiental nas instituições educativas 
do Programa de Pós-graduação em Educação nas Ciência. Cada estudante respondeu o questionário pelo formulário Google Forms e enviou-o para três (3) pessoas.

O questionário foi composto por questões objetivas referentes a dados de identificação (sexo, idade, formação, localização) e 12 questões sobre temáticas da EA e Objetivos do desenvolvimento sustentável (ODS).

Neste trabalho analisaram-se as respostas da questão número 3: "Como você define a EA". Das 80 pessoas que responderam o questionário, foram analisadas 38 respostas, chegou-se a esse número, selecionando professores do Ensino Fundamental II e que estão atuando diretamente em sala aula.

A organização e sistematização dos dados, está fundamentada nos argumentos de Moraes e Galiazzi (2016) sobre análise textual discursiva, a qual consiste em processo rigoroso, em que a interpretação dos pesquisadores carrega as concepções, discursos e ideias do investigador, ampliadas e reelaboradas durante o processo de construção do conhecimento. Ao analisar as respostas dos entrevistados com relação a sua concepção de EA, fundamentados nas contribuições de Guimarães (2007) e Loureiro (2007), identificamos duas subcategorias respectivamente: EA Conservadora e EA Crítica. Também foi identificado que muitos professores não conseguem definir EA. Estas reflexões também trazem para o debate a contribuições de Paulo Freire quanto ao referencial teórico e metodológico para as práticas educativas ambientais que se dão nos espaços educativos.

Os indivíduos participantes da pesquisa aceitaram participar e serão identificados com a letra Q: ( Q1; Q2 ....Q38) O Projeto inicial foi aprovado pelo Comitê de Ética na Pesquisa da Unijuí, identificado com o nº 3.642.360.

\section{Resultados e Discussão}

Participaram da pesquisa um total de 80 (oitenta) professores, porém fizemos um recorte para 38 (trinta e oito) professores. Esse recorte foi realizado tendo como foco os professores do Ensino Fundamental II que atuam diretamente em sala de aula. Então deste total, 31 (trinta e um) são mulheres e 7 (sete) homens. Essa predominância no sexo feminino corrobora os resultados obtidos pelo Censo do Professor (BRASIL. MEC/Inep/Deed, 2009), realizado em 2007, onde mais de 90\% dos professores brasileiros, que lecionam na educação básica, são mulheres.

A faixa etária dos entrevistados é bem variada: 3 (três) (8\%) deles possuem entre 17 e 25 anos, 9 (nove) (24\%) entre 26 e 35 anos e os 26 (vinte e seis) (58\%) professores restantes possuem mais de 36 anos. Para Crespo (2008, p. 65) "a idade é um fator preponderante com relação ao interesse nas questões ambientais". Em sua pesquisa constatou que ao longo de dez anos, está confirmado o fato de que os mais velhos (55 anos ou mais) têm menor interesse, independentemente da classe social e do nível de escolaridade.

Quanto ao tempo de atuação 7 (sete) 18\% estão atuando como professor entre 1 a 3 anos, 5 (cinco) 13\% atuam entre 4 a 6 anos, 6 (seis) 16\% atuam entre 5 a 9 anos, e os 20 (vinte) 53\% restantes atuam a mais de 10 anos.

Tratando especificamente do foco principal desta pesquisa, em relação a concepção de EA, as respostas que professores trouxeram como preocupação a preservação da natureza e a conscientização dos alunos em relação ao meio ambiente. Segundo Loureiro (2013) é uma tendência da EA conservadora quando:

Resultam em ações individuais e comportamentais no âmbito doméstico e privado, de forma a-histórica, apolítica, conteudística, instrumental e normativa. Ao adotarem uma perspectiva estritamente ecológica da questão ambiental, perdem de vista as dimensões sociais, políticas e ideológicas indissociáveis de sua gênese e dinâmica, porque não incorporam as posições de classe e as diferentes responsabilidades dos atores sociais enredados na crise ambiental. (p. 67)

$\mathrm{Na}$ maioria das respostas dos sujeitos desta pesquisa, expressam que as concepções de EA dos entrevistados trazem conceitos ou informações que dificilmente contribuem para a formação de cidadãos críticos, que possam através do conhecimento 
modificar valores e agir de maneira ética e coerente com relação as questões ambientais. Para reforçar essa premissa estabelecemos duas subcategorias baseadas nas respostas dos entrevistados e uma terceira possibilidade, que também classificaremos como subcategoria, pois, alguns professores não conseguiram definir EA. No Quadro 1, apresentamos as subcategorias identificadas e o mapeamento dos entrevistados:

Quadro 1. Subcategorias da categoria Concepções Críticas de Educação Ambiental, conforme análise das respostas dos professores do Ensino Fundamental-II, atuantes em sala de aula e que participaram da pesquisa.

\begin{tabular}{|l|l|c|c|}
\hline Categorias & Subcategorias & No de Entrevistados & Percentual (\%) \\
\hline Concepções de EA & $1.1-$ Conservadora & 19 & 50 \\
\cline { 2 - 4 } & $1.2-$ Crítica & 11 & 29 \\
\cline { 2 - 4 } & $1.3-$ Sem Definição & 8 & 21 \\
\hline
\end{tabular}

Fonte: Dados da pesquisa.

Nas respostas dos entrevistados está presente a concepção conservadora de EA, na qual predomina a ideia da preservação e da conservação do meio ambiente. Como os exemplos a seguir:

É aquela que busca formar, informar e mostrar a realidade do nosso ambiente. Como preservar, cuidar, proteger. A EA deve formar para os cuidados com o Meio Ambiente. (Q.18, de 7 a 9 anos de atuação como professor).

Uma disciplina que tem como objetivo ensinar para as pessoas sobre a importância da conservação do meio ambiente e o respeito à natureza. $(Q .29$, mais de 10 anos de atuação como professor).

São diretrizes e normas que trazem formas de preservação e conservação do meio ambiente como um todo. $(Q .38$, de 4 a 6 anos de atuação como professor).

Estas respostas demonstram que os professores tratam a EA com uma certa ingenuidade limitando-se ao entendimento de a conscientização ambiental é suficiente para resolver os problemas ambientais. Entendemos que é importante sensibilizar para a preservação, mas essa forma de abordar EA, demonstra que muitos professores não tem um embasamento teórico suficiente, que pode conduzir o professor a equívocos e a ineficiência de sua ação pedagógica. Freire (1991) reforça a ideia que a educação precisa ser abordada de forma a compreender o mundo e a natureza a partir das estruturas social, política e cultural.

Nunca pude entender a leitura e escrita da palavra sem a "leitura" do mundo que me empurrasse à "reescrita" do mundo, quer dizer, a sua transformação. E quando falo em mundo não falo exclusivamente das árvores e dos animais, que também amo, das montanhas dos rios. Não falo exclusivamente da natureza de que sou parte, mas das estruturas sociais, da política, da cultura, da história, de cuja leitura também faço parte. (p. 107).

A maioria dos professores apresentam dificuldades de compreenderem a essência da EA. Para Justen (2006) as visões mais comuns são práticas que orientam a destinação correta do lixo, o que não deixa de ser importante, mas enfoca somente um aspecto da problemática ambiental. Loureiro (2006, p. 47) concorda com essa ideia "coloca-se com frequência no cerne da EA a contemplação do natural e não a interação na natureza". Tanto, Justen (2006) e Loureiro (2007), enfatizam que a EA, em muitas escolas é abordada de maneira desconexa da realidade, pois estas tratam este tema na ótica do senso comum, deixando de refletir com profundidade as questões que evolvem o meio ambiente, esta abordagem dificulta ainda mais a construção de conhecimento.

De outro modo, temos uma parcela representativa dos professores entrevistados (29\%) que pensam a EA de maneira crítica, que percebem a importância de compreender e aprender a complexidade da EA, através da busca do diálogo entre ação- 
reflexão-ação em torno das vivências cotidianas. Nesse sentido, alguns professores aproximam suas respostas de uma concepção crítica de EA, como se observa:

É uma área de discussão sobre os entraves ambientais. No ensino está direcionada para praticas educativas de conscientização sobre os problemas ambientais, dialogando práticas de interposição crítica e reflexiva com atitudes pró ativas. (Q.04, de 1 a 3 anos de atuação como professor)

São ações através das quais os sujeitos constroem valores, conhecimentos, habilidades e competências voltadas à conservação do meio ambiente e sua sustentabilidade. (Q.10, mais de 10 anos de atuação como professor)

É o processo de orientação e colaboração na proteção do ambiente em que vivemos e na preservação de recursos naturais; quer seja por educar a terceiros ou pela sua própria participação no processo em busca da sustentabilidade. (Q.28, de 1 a 3 anos de atuação como professor)

Tais respostas demonstram que os professores entendem a EA como uma ação emancipatória, tematizando os problemas socioambientais vividos e percebidos na busca da transformação de seus ambientes de vida. Deixam claro que a EA não é um discurso genérico nem uma premissa de que todos são atingidos com a mesma intensidade pela degradação socioambiental, tratase de um importante instrumento no processo de conscientização socioambiental dos cidadãos em relação a sua comunidade e mundo. Conforme Loureiro (2013):

Essa tendência traz então uma abordagem pedagógica que problematiza os contextos societários em sua interface com a natureza. Por essa perspectiva, definitivamente não é possível conceber os problemas ambientais dissociados dos conflitos sociais; afinal, a crise ambiental não expressa problemas da natureza, mas problemas que se manifestavam na natureza. A causa constituinte da questão ambiental tem origem nas relações sociais, nos modelos de sociedade e de desenvolvimento prevalecentes. (p. 68)

No entanto, é preocupante constatar que $21 \%$ dos professores entrevistados não conseguiram definir EA, demostrando que não há um conhecimento real sobre ela, que pode ser resultado de um estudo muito superficial, percebe-se que falta entendimento do que realmente trata a EA. Essas lacunas preocupam, porque o conceito e a concepção de EA, afetam diretamente na prática pedagógica dos professores. Nesse sentido, Sato (2001b, p.24) afirma: "não temos dúvidas de que a EA exige um debate sobre suas bases de sustentação, com aberturas epistemológicas que confiram seu alto poder de diversidade e interfaces que a sua própria natureza requer". Conforme observamos em algumas respostas dos professores entrevistados com relação a definição de EA:

Necessária. (Q.11, mais de 10 anos de atuação como professor)

Precisa ter mais projeto voltado a EA. (Q.30, mais de 10 anos de atuação como professor)

Essencial. (Q.33, mais de 10 anos de atuação como professor)

Contudo, o que se tem percebido nas pesquisas neste campo, é que o domínio mínimo do conceito de EA, não está acontecendo na formação inicial dos professores. Várias pesquisas apontam a lacunas na abordagem da EA em cursos de formação inicial de professores. Entre essas pesquisas está a desenvolvida por Dickmann (2017). Segundo esse autor, nos cursos da universidade em que ele desenvolveu sua pesquisa, a EA tem uma abordagem precária no contexto curricular, estando fragmentada, a cargo de iniciativas pessoais de alguns professores.

Para que o professor possa amenizar essa lacuna, se faz necessário mais espaços de discussão e reflexão junto com seus colegas sobre a EA. Porém, o que se percebe no ambiente escolar é que há muitos problemas a serem resolvidos como por exemplo, a carga horária acentuada que não permite ao professor tempo e espaço para realizar mais estudos sobre a EA, embora 
alguns entendam que o conhecimento dos princípios fundamentais que a sustenta deve estar presente no cotidiano da escola. Conforme salienta Dickmann (2017):

A debilidade da presença da temática socioambiental nos currículos da formação inicial de educadores licenciados é algo ardilosamente orquestrado para que os profissionais da educação saiam dessa etapa formativa sem a condição de perceber as inter-relações ético-estético-político-pedagógico-culturais presentes na totalidade da realidade. Sem exagero, há uma malvadeza intrínseca na constituição de educadores com competência profissional duvidosa para o trabalho na escola, reforçando a máxima que estamos sempre repetindo: a escola é feita para não funcionar! (p. 64).

Estas respostas, confirmam a falta de embasamento teórico na formação inicial e/ou continuada dos professores pesquisados, quanto à concepção de EA e consequentemente, a uma prática significativa da EA. Esses professores apresentam dificuldades de compreenderem a essência da EA, o que reforça que o no seu processo formativo a EA foi tratada de forma desconexa da realidade, na ótica do senso comum, deixando de refletir com profundidade as questões que evolvem o meio ambiente, esta abordagem dificulta ainda mais a construção de conhecimento. Bornia e Royer (2020, p.13) também compactua com essa percepção e afirma que deve-se frisar a importância da formação de professores a fim de que estes possam atuar em distintos contextos e dimensões do processo educativo, bem como na EA.

Entendemos a EA como um processo que pode proporcionar uma compreensão crítica da sociedade e do mundo, com o objetivo de promover atitudes, numa perspectiva consciente e participativa, resgatando os valores da conservação dos recursos naturais, que vise melhorar a qualidade de vida dos seres humanos. A EA precisa estar presente nos diversos espaços sociais, culturais, políticos e educacionais, numa perspectiva global, como uma perspectiva que permeie todos os aspectos que abordem sociedade e natureza. Assim, a EA necessita ser abordada nos diversos aspectos e espaços promovendo a percepção do educando como cidadão. Tavares, Sousa e Santos (2018), em sua pesquisa, reforçam a ideia de que a educação pode contribuir na motivação de ações para uma sociedade sustentável:

[...] faz-se necessário medidas que visem combater, de forma urgente, esse descontrole da utilização dos bens que o meio ambiente oferece. A educação tratada como base, pode auxiliar desde cedo em um processo de compreensão sobre a sustentabilidade em todos seus âmbitos, onde a ideia central é partir da conscientização do indivíduo, para assim, iniciar um processo construtivo. (p.5)

Esta abordagem não pode ser confundida como somente transmissão de conhecimentos científicos e mera conservação da natureza, é preciso levar em conta aspectos políticos, socioeconômicos, e culturais para que realmente possa promover uma mudança de comportamento nas pessoas. Buscar essa transformação, significa adquirir o sentido dos valores sociais, embasado na concepção de que meio ambiente não é apenas a natureza, mas sim o lugar onde vivemos.

Percebe-se que EA muitas vezes é tratada com interesses políticos e econômicos, porém ela é uma opção pedagógica crítica aos modelos vigentes. Vários pesquisadores consideram a EA como um importante instrumento para uma educação crítica e emancipatória, que proporciona a participação política do cidadão, com o intuito de consolidar a democracia na busca por soluções dos problemas ambientais através da ética e o diálogo entre gerações e culturas. Assim, através da conscientização, da sensibilização e da busca pela mudança de comportamento, poderemos dar um passo adiante frente as questões ambientais que urgem por respostas concretas, nesse contexto podemos concluir que a EA é uma práxis educativa. 


\section{Considerações Finais}

O objetivo desta pesquisa foi refletir as diferentes concepções de EA, e entender como estão interferindo no trabalho do professor no espaço escolar. Bem como, fomentar as discussões acerca da EA Crítica e da EA conservadora, considerando que essas reflexões são difíceis de acontecerem naturalmente, mas tornam-se imprescindíveis na compreensão do conceito de EA. A deia é também fomentar possíveis diálogos e críticas entre a prática e as apropriações destes conceitos na busca da construção coletiva da cidadania socioambiental.

A EA, enquanto campo de pesquisa e reflexão sobre as relações sociedade-natureza tem encontrado fundamento e significação em diversas correntes de pensamento. Portanto, é de extrema importância que os educadores compreendam e aprendam a complexidade da EA, para que possa buscar o diálogo entre as diferentes abordagens, ou seja, se faz necessário que o educador ambiental se aproprie desses conceitos para colocar em prática na sua ação-reflexão-ação em torno das vivências cotidianas, dos saberes da experiência, frente a racionalizações descontextualizadas e delimitadoras do processo educativo.

Neste contexto a EA assume uma função importante na mediação entre culturas, saberes, comportamentos diferenciados e interesses de grupos sociais, para realizar as transformações necessárias na promoção de um desenvolvimento com maior sustentabilidade. Por isso, o meio ambiente deve ser entendido como responsabilidade de todos e a EA praticada de forma coletiva, ou seja, com a participação da sociedade teremos mais chance de encontrar alternativas na solução dos problemas ambientais.

Portanto, entendemos que é viável trabalhar o conceito de EA além da sala de aula, proporcionando o envolvimento das pessoas em discussões e práticas que apontem a transformação da realidade. Essa ideia aponta a necessidade de promover uma prática educativa que venha romper com as concepções tradicionais de educação, pois trabalhar a EA, exige desenvolver métodos em que os indivíduos tomem consciência dos seus atos, sem perder a coletividade. Trabalhar nesta perspectiva requer que os envolvidos no processo, principalmente os professores, a compreendam como um ato político voltado para a transformação social.

Diante dessas constatações apontadas nesta pesquisa, percebemos a necessidade de implementar a EA crítica em todos os processos educativos, mas para isso se faz necessário reavaliar os objetivos das práticas de EA, tendo como ponto de partida a problematização da realidade. No entanto, se faz urgente uma reavaliação do currículo escolar, visualizando as causas que levaram à configuração da EA no contexto escolar atual, e por fim, a motivar a participação dos professores em espaços públicos como conselhos, fóruns, comitês, agendas, entre outros, para, desse modo, interagir com as políticas públicas educação e consequentemente nas de EA. Com as reflexões apontadas aqui, espera-se fomentar outras pesquisas no que se refere a EA, como por exemplo: abordagens da EA na formação inicial e continuada de professores; práticas pedagógicas desenvolvidas em sala de aula ou fora dela; a relação entre professor e aluno na perspectiva da EA, entre tantos outros. Pois, a EA precisa ser abordada com o objetivo de capacitar professores e alunos de forma que consigam compreender a importância de pensar e agir em relação à preservação e à conservação, que tragam alternativas de sustentabilidades, onde a escola seja o espaço que formará esses cidadãos.

\section{Referências}

Bornia, B. G., \& Royer, M. R. (2020). Pesquisas brasileiras em Educação Ambiental que estão em voga atualmente: Uma análise de periódicos nacionais. Research, Society and Development, 9(4).

Brasil. (1999). Política Nacional de EA. Lei 9.795, de 27 de abril de 1999.

Brasil. (2001). Parâmetros Curriculares Nacionais: Meio Ambiente e Saúde. Ministério da Educação. Secretaria da Educação Fundamental. (3a ed.), A Secretaria, 2001.

Brasil. (1998). Parâmetros Curriculares Nacionais: terceiro e quarto ciclos do ensino fundamental. MEC/SEF, 1998. 
Brasil. (2009) MEC/Inep/Deed. Estudo exploratório sobre o professor brasileiro com base nos resultados do Censo Escolar da Educação Básica 2007. Instituto Nacional de Estudos e Pesquisas Educacionais Anísio Teixeira. Inep, 2009. 63 p

Brasil. (1988). Constituição da República Federativa do Brasil de 1988.

Carvalho, I. C.M. (2004). Educação ambiental crítica: nomes e endereçamentos da educação. In: Layrargues, P. P. (org). Identidades da Educação Ambiental Brasileira. Ministério do Meio Ambiente, 2004.

Dickmann, I. (2017). Pedagogia da (in)disciplina ambiental: desafios político-pedagógicos na formação de educadores ambientais no ensino superior Revista Eletrônica do Mestrado em Educação Ambiental, Rio Grande, Edição especial XVI Encontro Paranaense de EA, 55-70.

Dickmann, I \& Carneiro, S. M. M. (2012). Paulo Freire e Educação Ambiental: contribuições a partir da obra Pedagogia da Autonomia. Revista de Educação Pública, 21(45), 87-102.

Freire, A. M. (2007). Educação para a Sustentabilidade: Implicações para o Currículo Escolar e para a Formação de Professores. Revista Pesquisa em Educação Ambiental, 2(1), 141-154.

Freire, P. (1996). Pedagogia da Autonomia: Saberes necessários à prática educativa. Paz e Terra, 1996. 168 p.

Freire, P. (2000). Pedagogia da indignação: cartas pedagógicas e outros escritos. Apresentação de Ana Maria Araújo Freire. Carta-prefácio de Balduino A. Andreola. Editora UNESP, 2000.

Gadotti, M. (1991). Convite à Leitura de Paulo Freire. (2a ed.), Scipione, 1991

Guimarães, M. A. (2007). Formação de Educadores Ambientais. (3a ed.), Papirus. 2007.

Justen, L. M. (2006). Trajetórias de um grupo interinstitucional em um programa de formação de educadores ambientais no estado do Paraná (1997-2002). Educar em Revista, (27), 129-145.

Layrargues, P. P. (2007). As desafiantes novidades da Educação Ambiental: Há uma generalizada incompreensão do significado das correntes pedagógicas? In: GUIMARÃES, M. A Formação de Educadores Ambientais. (3a ed.), Papirus.

Layrargues, P. P. \& Lima, G. F. C. (2014). As macrotendências político-pedagógicas da educação ambiental brasileira. Revista Ambiente e Sociedade. XVII(1), 23-40.

Loureiro, C. F. B., Trein E., Tozoni-Reis M. F. C. \& Novicki, V. (2009) Contribuições da Teoria Marxista para A Educação Ambiental Crítica In. Cad. Cedes, 29(77), 81-97.

Loureiro, C. F. B. \& Layrargues P.P. (2013). Ecologia Política, Justiça e Educação Ambiental Crítica: Perspectivas de Aliança Contra-Hegemônica. Trab. Educ. Saúde, 11(1), 53-71.

Loureiro, C. F. B. (2006). Crítica ao fetichismo da individualidade e aos dualismos na Educação Ambiental. Educar em revista, (27), $37-53$.

Loureiro, C. F. B. (2009). Trajetória e fundamentos da Educação Ambiental. (3a ed.), Cortez, 2009.

Loureiro, C. F. B. (2007). Educação Ambiental Crítica: contribuições e desafios. In: BRASIL. Vamos Cuidar do Brasil: Conceitos e práticas em Educação Ambiental na Escola. Ministério da Educação. 2007.p.57-64.

Moraes, R., Galiazzi M. C. (2016). Análise textual discursiva. (3a ed.), Ed. Unijuí, 264 p.

Sato, M. (2001) Apaixonadamente Pesquisadora em Educação Ambiental. Educação: Teoria e Prática, 9(16), 24-35.

Sato, M. (2001). Debatendo os desafios da EA. In: Congresso de EA Pró Mar de Dentro, 1. 2001a. Rio Grande. Anais... Rio Grande: Mestrado em EA, FURG \& Pró Mar de Dentro.

Sato, M. \& Carvalho, I. (2009). Educação Ambiental: pesquisa e desafios. Artmed.

Sauvé, L. (2011). Uma cartografia das correntes em educação ambiental. In: Sato, M., \& Carvalho, I. Educação Ambiental: pesquisa e desafios. Artmed. p.1744.

Santos, D. A., \& Bomfim, A. M. Educação Ambiental Crítica e Mídia: o discurso da sustentabilidade na propaganda "Casa Ecológica”. In: Encontro Nacional De Pesquisa Em Educação Em Ciências, 8., 2011, Campinas. Anais eletrônicos... Campinas: UNICAMP, 2011.

Tavares, F. B., Sousa, F. C. F., \& Santos, V. E. S. (2018). A educação ambiental com perspectiva transdisciplinar no contexto da legislação brasileira. Research, Society and Development, 7(12), 01-22.

Tristão, M. (2008). A educação ambiental na formação de professores: redes de saberes. (2a ed.), Annablume, Facitec.

Vasques C. C. \& Messeder J. C. (2020). Educação Ambiental em uma perspectiva reflexiva na Educação de Jovens e Adultos. Research, Society and Development, $9(8)$. 